\title{
Conductive Paths and Connections on Polymer Substrates for Structural Electronics
}

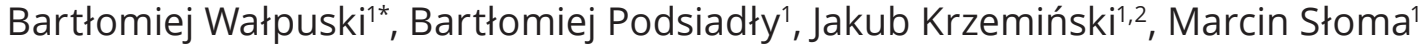 \\ 1 Institute of Metrology and Biomedical Engineering, Warsaw University of Technology, Warsaw, 02-225, Poland \\ 2 Centre for Advanced Materials and Technologies CEZAMAT, Warsaw University of Technology, Warsaw, 02-822, Poland \\ *Corresponding author, e-mail: b.walpuski@mchtr.pw.edu.pl
}

Received: 29 November 2018, Accepted: 25 January 2019, Published online: 28 March 2019

\begin{abstract}
Structural Electronics is a modern, still developing technique of manufacturing electrical circuit merged with a mechanical construction of device. This approach opens new possibilities like higher components density, cost effective short series and prototypes or manufacturing of electronics in almost any place like third world countries or space station. In this paper, a novel method of fully printed electronic devices manufacturing is presented. Use of specially prepared paste with silver nanoparticles and microflakes, whose manufacturing procedure is described, as well as sintering with near infrared, continuous wave laser allows to get less than $35 \mathrm{~m} \Omega$ electrical resistivity of a 1206 SMD resistor single joint. Different 3D printed substrates were tested as well as mechanical and electrical properties of joints were measured. Finally, a simple circuit with LEDs is manufactured, demonstrating the practical used of the presented technique.
\end{abstract}

\section{Keywords}

structural electronics, laser sintering, additive manufacturing, nanosilver conductive paste

\section{Introduction}

Structural electronics is an extension of printed circuit boards (PCB) which are base of every electronic device. PCB can be found in every factory, most vehicles, household goods or even in the majority of people pocket. Due to its popularity, recent researches were focused on increasing efficiency and reducing costs $[1,2]$. Despite the first patents of manufacturing PCB was submitted almost century ago [3], there are still issues that need to develop like prototyping and short-run production methods or environment-friendly manufacturing [4]. These goals perfectly meet structural electronics approach. It is true that PCB prototyping methods have been developed, but existing solutions are based on subtractive methods like CNC machining [5] or laser engraving [6] and what is more they cannot be used in multilayer applications.

The guiding idea of structural electronics is integrating electrical components like resistors, capacitors, integrated circuits etc. with mechanical parts of device (for example casings or objects body). Electronics parts and traces can be conformally placed on the surface or embedded inside the volume of device, what can be done by additive manufacturing methods. 3D printing is a group of additive techniques created especially for prototyping mechanical parts, thus they meet perfectly set requirements. The development of these methods leads to using their not only in design offices but even final products can be made this way [7]. Today 3D printed products can be found in many industries: from aerospace [8], through automotive and medicine [9] to civil engineer [10] and gastronomy [11, 12]. No wonder then attempts of 3D printed electronics were made. They are two common approaches to this issue. First one is building a non-conductive structure with channels in place of paths and then, after printing filling them with room temperature liquid alloy, like Galinstan $[13,14]$. Second one presents alternately printing of structural materials and conductive paths (usually polymer composite like isotropic conductive adhesive or conductive ink) in every layer [15-17]. Both of these solutions have disadvantages: conductivity of used materials (liquid metal and conductive inks/adhesives) is significantly lower (about $2 \cdot 10^{6} \mathrm{~S} / \mathrm{m}[17,18]$ ) then the conductivity of widely used in electronics metal- copper. What is more polymer composites are unstable in temperature over $200{ }^{\circ} \mathrm{C}$ [19] which can be excited during a 3D printing process. Another drawback of a liquid alloy is a minimal adhesive force between electronic components 
and a possibility of leaking metal out especially near connectors or switches. For these reasons, it was decided to develop a different type of material based on silver nanoparticles.

Silver nanoparticles (Ag NP) are gaining more and more popularity as a base of modern pates for electronic joints [20-22]. The biggest advantage of them is fact that sintering temperature (usually about $250-300{ }^{\circ} \mathrm{C}$ ) is much lower than the maximum service temperature (even over $900{ }^{\circ} \mathrm{C}$ [20]). This unusual property is a result of using nanomaterial: melting point of nanoparticles (paste before sintering) is significantly lower than melting point of bulk material (joint after sintering) [23-25]. What is more, silver is metal with the lowest electrical resistivity $\left(1.59 \cdot 10^{-8} \Omega \cdot \mathrm{m}[16]\right)$, thus Ag NP based paste is excellent material also for temperature stable electronic circuits. In this paper process of preparing Ag NP based paste and method of manufacturing electronic circuit on 3D printed substrates from that paste is presented. Also a three different substrate materials are tested and properties of joints with an electrical components are verificate.

\section{Materials and Methods}

Production of structural electronics requires developing of new manufacturing methods. Presented solution is based on additive manufacturing extended by thick-film technology and surface-mount devices. Established fabrication process consists of six steps presented on the Fig. 1.

The first step is printing substrate plate by Fused Deposition Modelling (FDM) one of additive manufacturing technique. Groups of materials which can be $3 \mathrm{D}$ printed is limited and what is more, substrates usually used in electronics (like FR4, G10 or Teflon) cannot be additively manufactured. Thus in this stage three polymer materials was tested: poly(lactic acid) (PLA) the most popular material in both industrial and desktop Fused Deposition Modelling (FDM) printers, ULTEM polymer with have one of the highest performance from available material and HP 3D High Reusability PA 12 (HPPA) - a material for Multi Jet Fusion (MJF) printer, which is one of the most precise system commercially available on the market, both (material and printer) developed by Hewlett-Packard. From these materials substrate plates with dimension of $37.5 \times 25 \times 2.5 \mathrm{~mm}$ and $100 \%$ infill was printed.

On the top of each plate a circuit pattern was made by screen printing of a non-commercial conductive paste designed and manufactured on the Faculty of Mechatronics

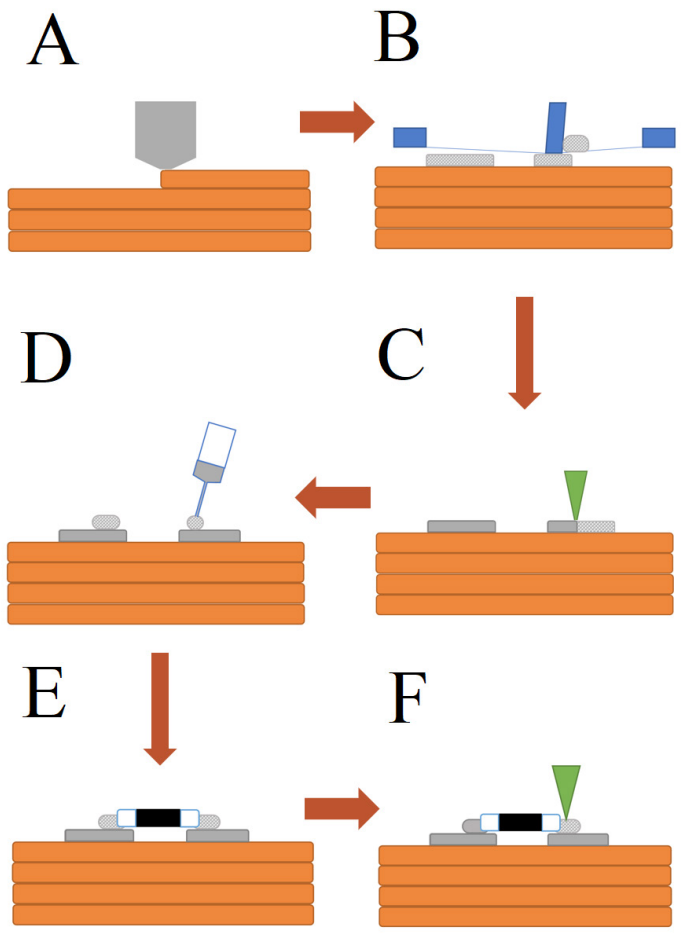

Fig. 1 Scheme of a developed manufacturing process: A. 3D printing of a polymer substrate; B. The circuit pattern screen printing; C. Laser sintering of printed paste; D. Dispensing paste on pads; E. Placing a SMD components; F. Laser sintering of connections.

Warsaw University of Technology in Poland. Conductive component of this material is mixture of silver nanoparticles (with size $30.5 \pm 5.4 \mathrm{~nm}$ ) and silver microflakes of average size $3 \mu \mathrm{m}$ and thickness $100 \mathrm{~nm}$. Silver nanoparticles were coated with salts of palmitic acid to prevent from room temperature agglomeration. To achieve rheology parameters suitable for screen printing, silver powders was suspended in toluene and dispersed in the organic vehicle. After testing it was decided to choose $8 \%$ wt. solution of poly(methyl methacrylate) (with average molar mass Mw 350,000, delivered by Sigma-Aldrich) in [2-(2-Butoxyethoxy)ethyl] acetate. More details about this paste can be found in [26] and final composition is: silver nanopowders (14\% wt.), silver microflakes (59\% wt.), organic vehicle (20\% wt.), organic residues (7 \% wt.). Then described paste was screen printed on top of each plate by using polyethylene screen with 175 mesh.

Paste after print needs to be heat cured and usually it is done by heating in oven at $300{ }^{\circ} \mathrm{C}$. In this case such high temperature can damage substrate plates, thus, a novel method base on laser scanning was developed. The laser diode at $808 \mathrm{~nm}$ wavelength was mounted on a 3axies cnc machine and used as a local heat source to sinter a 
paste layer. Density of power in $200 \mu \mathrm{m}$ spot was about $250 \mathrm{~W} / \mathrm{mm}^{2}$ and scanning was performed with a speed of $1000 \mathrm{~mm} / \mathrm{s}$ and $100 \mu \mathrm{m}$ hatch distance. Using of laser beam allows to achieve a high temperature gradient during a heat treatment and obtain a fully sintered silver layer without significantly damaging the substrate. The next step was assembly of electronical components- SMD 1206 resistors. Silver paste described above was used as binding agent and dispensed from syringe on pads. Then resistors was placed on wet paste, which finally was laser sintered to make electrical and mechanical connections between pads and components.

On obtained joints to types of measurements were taken: electrical and mechanical. Resistance of single joint was measured by a 4-wire method with the Escort 3145A multimeter. For each substrate material 8 samples was prepared, thus 16 joints was tested. Then mechanical properties of manufactured joints were verificated in the shear test with registered force needed to break a connection. In this test 8 samples for each substrate was measured.

\section{Results}

For each substrate material average joint resistance and standard deviation of it are shown in a Fig. 2A. We can see, that for joints made on a ULTEM substrate have the highest standard deviation, over $50 \%$ of average $(34 \mathrm{~m} \Omega$ $\pm 18 \mathrm{~m} \Omega$ ). That means that these results are uncertain and for this polymer a sintering process are not so stable like for PLA or HPPA. Opposite outcomes obtained for PLA: an average resistance was relatively high, but a standard deviation of it is the lowest for these measurements (60 $\mathrm{m} \Omega \pm 11 \mathrm{~m} \Omega$ ). Properties of joints made on a HPPA are between PLA and ULTEM: noticed $42 \mathrm{~m} \Omega \pm 16 \mathrm{~m} \Omega$.

Data obtained in shear test are presented in a Fig. 2B. We observe that the most durable connection was made on a PLA and average force was $50 \mathrm{~N} \pm 12 \mathrm{~N}$. On the opposite side was results observed for a ULTEM base circuits: 14.4 $\mathrm{N} \pm 2.6 \mathrm{~N}$. Attributes of a HPPA as a substrate was again between rest two polymers: recorded average force $28.2 \mathrm{~N}$ with $7.8 \mathrm{~N}$ standard deviation.

Collected data show us that none of tested substrate material are significantly better than others: all of them have advantages in one field and cons in others. On the other hand in structural electronics mechanical durability aren't so crucial because all electrical components are surrounded by structural material. However, connections on ULTEM substrate still have big range of obtained resistance, what can be troubling in some applications. Another important attribute of tested materials is availability
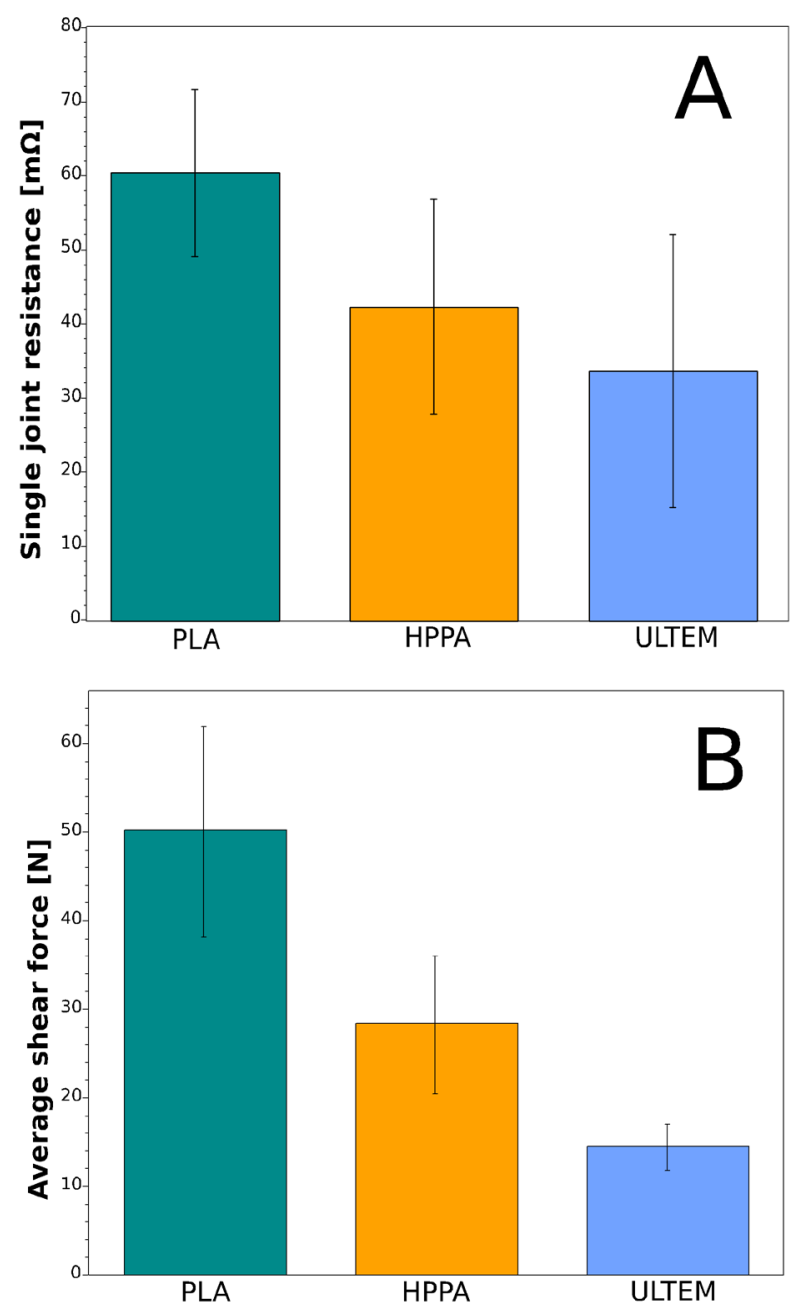

Fig. 2 Electrical (A) and mechanical (B) properties of the 1206 SMD resistor joints made by laser sintering of nanosilver paste on different polymer substrates.

of device which can print from them: using ULTEM or HPPA require specific printer, manufactured only by individual companies. Only a PLA polymer can be processed by countless and constantly increasing number of printers.

To demonstrate the possibility of practical use of this technology, we build simple hybrid circuit with a SMD LEDs on PLA substrate plate (shown in Fig. 3).

\section{Conclusions}

The technique of a fully additive manufacturing of electronic circuit was presented. Conductive paste based on silver nanoparticles and microflakes was developed, which was used to produce pads, paths and joints with electrical components. Three different substrate materials was tested and dissimilar properties in electrical and mechanical field was observed: highest mechanical durability was noticed for circuits made on PLA but at the same time 


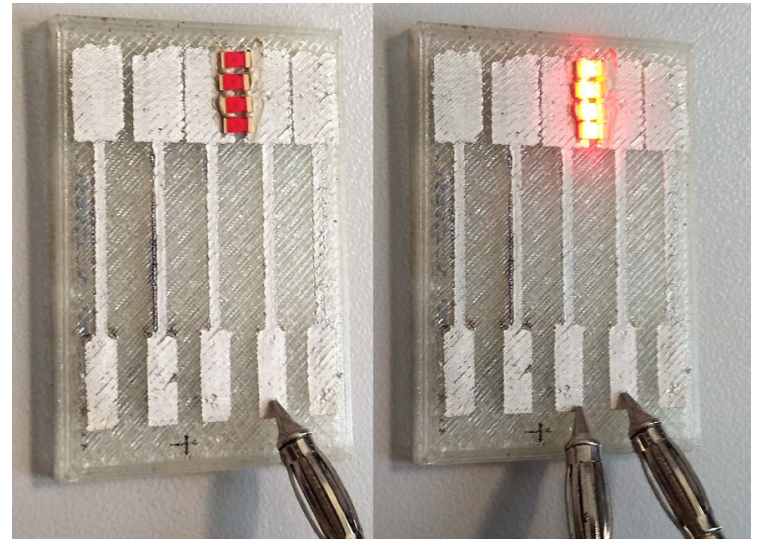

Fig. 3 Circuit manufactured on PLA 3D printed substrate by laser sintering of SMD LEDs to screen-printed nanosilver paste pads cured by laser.

\section{References}

[1] Perunović, Z., Mefford, R., Christoffersen, M., McIvor, R., Falls, D. "An analysis of vendor innovation capability in the contract electronics manufacturing industry", Production Planning \& Control, 27(10), pp. 797-809, 2016.

https://doi.org/10.1080/09537287.2016.1139210

[2] Korshunov, G. I., Petrushevskaya, A. A., Lipatnikov, V. A., Smirnova, M. S. "Development strategy and process models for phased automation of design and digital manufacturing electronics", IOP Conference Series: Materials Science and Engineering, 327(2), p. 022062, 2018.

https://doi.org/10.1088/1757-899X/327/2/022062

[3] Ducas, C. "Electrical apparatus and method of manufacturing the same", 1925, USA, US1563731A. [online] Available at: https://patents.google.com/patent/US1563731 [Accessed: 28 November 2018]

[4] Mosses, R., Brackenridge, S. "A novel process for the manufacturing of advanced interconnects", Circuit World, 29(3), pp. 18-21, 2003.

https://doi.org/10.1108/03056120310460775

[5] Salihmuhsin, M., BabA, S., Yilmaz, A. S., Sekkeli, M. "Design and Implementation of an Automated PCB Drawing and Drilling System", Uluslararası Mühendislik Araştırma ve Geliştirme Dergisi, 4(2), pp. 43-45, 2012. [online] Available at: http://dergipark. gov.tr/umagd/issue/31724/346040 [Accessed: 28 November 2018]

[6] Nowak, M., Antończak, A., Kozioł, P., Abramski, K. "Laser prototyping of printed circuit boards", Opto-Electronics Review, 21(3), pp. 320-325, 2013.

https://doi.org/10.2478/s11772-013-0096-4

[7] Mueller, B. "Additive Manufacturing Technologies - Rapid Prototyping to Direct Digital Manufacturing", Assembly Automation, 32(2), p. aa.2012.03332baa.010, 2012. https://doi.org/10.1108/aa.2012.03332baa.010

[8] Frazier, W. E. "Metal Additive Manufacturing: A Review", Journal of Materials Engineering and Performance, 23(6), pp. 1917-1928, 2014.

https://doi.org/10.1007/s11665-014-0958-z single joint electrical resistance was $50 \%$ or more higher than for circuits based on others polymers. Nevertheless PLA is also easily accessible and can be processed by popular desktop 3D printers, thus we think that this material is the most suitable for further research.

\section{Acknowledgement}

This research is part of the "Functional heterophase materials for structural electronics" project carried out within the First TEAM/2016-1/7 programme of the Foundation for Polish Science co-financed by the European Union under the European Regional Development Fund. It was also supported by the Institute of Metrology and Biomedical Engineering, Warsaw University of Technology.

[9] Mannoor, M. S., Jiang, Z., James, T., Kong, Y. L., Malatesta, K. A., Soboyejo, W. O., Verma, N., Gracias, D. H., McAlpine, M. C. "3D Printed Bionic Ears", Nano Letters, 13(6), pp. 2634-2639, 2013. https://doi.org/10.1021/n14007744

[10] Rutkin, A. "Watch as the world's first 3D-printed house goes up", New Scientist, 221(2960), pp. 24, 2014. https://doi.org/10.1016/S0262-4079(14)60529-7

[11] Tran, J. L. "3D-Printed Food", Minnesota Journal of Law, Science and Technology, 17(2), pp. 855-880, 2016. [online] Available at: https://scholarship.law.umn.edu/mjlst/vol17/iss2/7 [Accessed: 28 November 2018]

[12] Godoi, F. C., Prakash, S., Bhandari, B. R. "3d printing technologies applied for food design: Status and prospects", Journal of Food Engineering, 179, pp. 44-54, 2016. https://doi.org/10.1016/J.JFOODENG.2016.01.025

[13] Wu, S.-Y., Yang, C., Hsu, W., Lin, L. "3D-printed microelectronics for integrated circuitry and passive wireless sensors", Microsystems \& Nanoengineering, 1, pp. 2015013, 2015. https://doi.org/10.1038/micronano.2015.13

[14] Ota, H., Emaminejad, S., Gao, Y., Zhao, A., Wu, E., Challa, S., Chen, K., Fahad, H. M., Jha, A. K., Kiriya, D., Gao, W., Shiraki, H., Morioka, K., Ferguson, A. R., Healy, K. E., Davis, R. W., Javey, A. "Application of 3D Printing for Smart Objects with Embedded Electronic Sensors and Systems", Advanced Materials Technologies, 1(1), pp. 1600013. 2016. https://doi.org/10.1002/admt.201600013

[15] MacDonald, E., Salas, R., Espalin, D., Perez, M., Aguilera, E., Muse, D., Wicker, R. B. "3D printing for the rapid prototyping of structural electronics", IEEE Access, 2, pp. 234-242, 2014. https://doi.org/10.1109/ACCESS.2014.2311810

[16] Joe Lopes, A., MacDonald, E., Wicker, R. B. "Integrating stereolithography and direct print technologies for 3D structural electronics fabrication", Rapid Prototyping Journal, 18(2), pp. 129$143,2012$.

https://doi.org/10.1108/13552541211212113 
[17] Espalin, D., Muse, D. W., MacDonald, E., Wicker, R. B. "3D Printing multifunctionality: structures with electronics", The International Journal of Advanced Manufacturing Technology, 72(5-8), pp. 963-978, 2014.

https://doi.org/10.1007/s00170-014-5717-7

[18] Liu, T., Sen, P., Kim, C.-J. "Characterization of Nontoxic LiquidMetal Alloy Galinstan for Applications in Microdevices", Journal of Microelectromechanical Systems, 21(2), pp. 443-450, 2012. https://doi.org/10.1109/JMEMS.2011.2174421

[19] Illés, B., Krammer, O., Géczy, A., Garami, T. "Characterizing the conductivity of ICA joints by the mean intercept length of Ag flakes", Soldering \& Surface Mount Technology, 28(1), pp. 2-6, 2016.

https://doi.org/10.1108/SSMT-10-2015-0030

[20] Guo, W., Zeng, Z., Zhang, X., Peng, P., Tang, S. "Low-Temperature Sintering Bonding Using Silver Nanoparticle Paste for Electronics Packaging", Journal of Nanomaterials, 2015, pp. 1-7, 2015. https://doi.org/10.1155/2015/897142

[21] Yan, J., Zhang, D., Zou, G., Liu, L., Bai, H., Wu, A., Zhou, Y. N. "Sintering Bonding Process with Ag Nanoparticle Paste and Joint Properties in High Temperature Environment", Journal of Nanomaterials, 2016, pp. 1-8, 2016. https://doi.org/10.1155/2016/5284048

[22] Zhang, P., Wei, R., Zeng, J., Cai, M., Xiao, J., Yang, D. "Thermal Properties of Silver Nanoparticle Sintering Bonding Paste for High-Power LED Packaging", Journal of Nanomaterials, 2016, pp. 1-6, 2016.

https://doi.org/10.1155/2016/8681513
[23] Moon, K.-S., Dong, H., Maric, R., Pothukuchi, S., Hunt, A., Li, Y., Wong, C. P. "Thermal behavior of silver nanoparticles for low-temperature interconnect applications", Journal of Electronic Materials, 34(2), pp. 168-175, 2005. https://doi.org/10.1007/s11664-005-0229-8

[24] Jiang, Q., Zhang, S. H., Li, J. C. "Grain size-dependent diffusion activation energy in nanomaterials", Solid State Communications, 130(9), pp. 581-584, 2004.

https://doi.org/10.1016/J.SSC.2004.03.033

[25] Zhang, M., Efremov, M. Y., Schiettekatte, F., Olson, E. A., Kwan, A. T., Lai, S. L., Wisleder, T., Greene, J. E., Allen, L. H. "Size-dependent melting point depression of nanostructures: Nanocalorimetric measurements", Physical Review B, 62(15), pp. 10548-10557, 2000. https://doi.org/10.1103/PhysRevB.62.10548

[26] Kiełbasiński, K., Szałapak, J., Jakubowska, M., Młozniak, A., Zwierkowska, E., Krzemiński, J., Teodorczyk, M. "Influence of nanoparticles content in silver paste on mechanical and electrical properties of LTJT joints", Advanced Powder Technology, 26(3), pp. 907-913, 2015.

https://doi.org/10.1016/j.apt.2015.03.007 